\title{
SOLVENT-FREE SYNTHESIS OF AMIDE: A NOVEL TECHNIQUE OF GREEN CHEMISTRY
}

\author{
CHIRAGKUMAR J GOHIL ${ }^{1 *}$, MALLESHAPPA N NOOLVI²
}

${ }^{1}$ Discipline of Pharmacy, Gujarat Technological University, Ahmedabad, Gujarat, India. ${ }^{2}$ Department of Pharmaceutical Chemistry, Shree Dhanvantary Pharmacy College, Surat, Gujarat, India. Email: gohil2711@gmail.com

Received: 02 January 2021, Revised and Accepted: 16 March 2021

ABSTRACT

Objective: Amide is one of the most important functional group presents in the chemicals, pharmaceuticals, and foods. Conventionally, it has been synthesized from the carboxylic acid and amines. This conventional reaction is lengthy and involves hazardous chemicals and solvents. Hence, it poses waste management, solvent removal, and environmental issues to the industries. To overcome this limitation, we have reported the green chemistrybased method for the synthesis of amide from carboxylic acid and urea.

Methods: In this reaction, we have used boric acid as a catalyst, it is a simple and readily available compound. It is simple, efficient, and solvent-free procedure which involves the trituration of the reactant mixture and subsequent, direct heating of the triturated mixture.

Results: The rate of reaction is very high and can synthesize the amide quickly.

Conclusion: Various amides were prepared in good yield by this technique.

Keywords: Carboxylic acid, Urea, Boric acid, Amides, Green chemistry, Solvent-free method, Trituration and direct heating

(C) 2021 The Authors. Published by Innovare Academic Sciences Pvt Ltd. This is an open access article under the CC BY license (http://creativecommons.org/ licenses/by/4.0/) DOI: http://dx.doi.org/10.22159/ajpcr.2021v14i5.40688. Journal homepage: https://innovareacademics.in/journals/index.php/ajpcr

\section{INTRODUCTION}

Amides are a kind of organic compound or functional group which is most frequently found in the biological system, natural products, agrochemicals, polymers, and of course, in the pharmaceuticals [1-3]. Amide is a key intermediate in the synthesis of various bioactive molecules [4]. Amide or peptide bond is very much important for the drug synthesis and pharmaceutical industries [5]. Hence, amide synthesis is much concern in chemistry [6].

In general, amides are synthesized from the acid and amines. This reaction requires the activation of the carboxyl group. Activation of the carboxylic group can be done by converting the carboxylic group into the acyl halide, acyl azide, anhydride, and ester or by coupling reagents [7]. The most preferred process of the amide synthesis involves the conversion of acid into the acyl chloride and then this acyl chloride will react with the amine to give the amide [8] (Scheme 1).

However, this conventional reaction requires some of the hazardous and toxic reagents such as thionyl chloride, oxalyl chloride, and phosgene [9]. The various conventional methods have required the 6-16 $\mathrm{h}$ for the synthesis of amide.

Hence, it is a longer, tedious, and costly method. Moreover, at the industrial level, this reaction of the amide synthesis has produced hazardous waste. Moreover, pose the serious issue of waste disposal, waste solvent management, and increase the costs of waste disposal.

Therefore, it has required the atom economic, easy, convenient, and mild reaction for the amide synthesis $[10,11]$.

\section{Greener approach for the synthesis}

The use of toxic and hazardous solvents for the synthesis of chemicals arises environmental problems and waste management issues in industries. Hence, solvent-free or solid-state reaction is a potential alternative. Solvent-free or solid-state reaction are kinds of reaction which is occur in the absence of solvent [12].

Solvent-free direct solid-solid reaction is a greener approach for synthesis. Moreover, it obeys $1,2,3,4,5,6,8,9$, and $12^{\text {th }}$ principles of green chemistry [13].

Number of reactions can be done without the use of solvent [14]. Conventional reaction requires the workup and isolation of the solvent from the product, but solid-state reaction does not require it. Hence, it is economically cheap and easy to handle.

Advantages of solvent-free or solid-state or dry media reaction are as follow:

- Greener reaction

- Eco-friendly

- Minimize the waste or effluents

- Easy to handle

- Cheaper

- High rate of reaction

- High purity of product.

Herein, we report the solvent-free method for the synthesis of amides by direct reaction of acid and urea in the presence of boric acid (Scheme 2).

The scope of boric acid-catalyzed amidation has been discussed by various researchers [15]. Many pharmaceutical ingredients and steroid derivatives have synthesized by boric acid-catalyzed reactions [15].

Boric acid is cheap, readily available, and environmentally friendly compound. Moreover, urea is a good source of ammonia under solventfree conditions [16].

The reported method in this study is a greener technique for the synthesis of amides by mixing and trituration of carboxylic acid, urea, and boric acid followed by direct reaction of the triturated mixture without the solvent. 


\begin{tabular}{|c|c|c|c|c|c|}
\hline $\mathrm{R}-\mathrm{COOH}$ & $\stackrel{\mathrm{SOCl}_{2}}{\longrightarrow}$ & $\mathrm{R}-\mathrm{COCl}$ & $\stackrel{\text { aq. } \mathrm{NH}_{3}}{\longrightarrow}$ & $\mathrm{R}-\mathrm{CONH}_{2}$ & (Reaction time: 6-16 hrs) \\
\hline & & acetyl chloride & & amide & \\
\hline
\end{tabular}

Scheme 1: Conventional method of amide synthesis

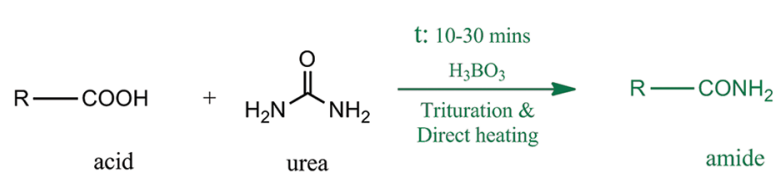

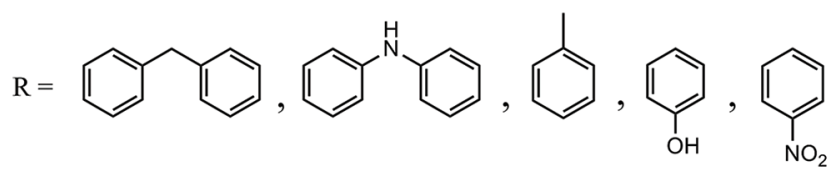

Scheme 2: Greener method for amide synthesis (solvent-free direct heating)

\section{METHODS}

Experimental

All the chemicals and reagents/solvents were obtained from the commercial suppliers with high purity. The chemicals and reagents/ solvents were used as received without further purification.

All the melting points were determined in one end open capillary tubes on a liquid paraffin bath and are uncorrected. The ${ }^{1} \mathrm{H}$ spectra were recorded in DMSO, using a Bruker $400 \mathrm{MHz}$ FT-NMR Spectrometer Avance III, the solvents and reagents were used without further purification.

\section{General procedure for the synthesis of the amides}

Weigh the carboxylic acid $(0.06 \mathrm{~mol})$, urea, and boric acid. The weigh amount was thoroughly mixed and triturated the mixture in mortar and pestle for 2-5 min. The triturated mixture was transferred into the beaker and was directly heated without the solvent at the $160-180^{\circ} \mathrm{C}$ for 10-30 min. During the course of reaction, the reaction mixture was completely melted and then reappeared as product (amide). Heating was removed and product (amide) was allowed to cool to room temperature. The aqueous ammonia solution (50-55 ml) was added to the crude product and heated with stirring, so unreacted acid was removed. Heating was stopped and filter to give a product. The collected product (amide) was successively washed with distilled water $(100 \mathrm{ml})$ to remove residual boric acid and dried the product/amide at room temperature to give a corresponding amide with high purity.

Proportion ratio of urea and boric acid for any given acid:

g of acid * $1.5=$ Quantity of Urea, $g$ of acid * $0.4=$ Quantity of Boric acid.

\section{2,2-Diphenylacetamide (C 01): Amorphous white}

Diphenylacetic acid (12.67 g, $0.06 \mathrm{~mol})$, urea (19 g), and boric acid $(5.06 \mathrm{~g})$ were mixed and triturated the mixture for $2-5 \mathrm{~min}$. Then, the triturated mixture was directly heated without the solvent at the $160-$ $180^{\circ} \mathrm{C}$ for $20-25$ mins. During the course of reaction, the reaction mixture was completely melted and then reappeared as product. Heating was removed and product was allowed to cool to room temperature. The aqueous ammonia solution $(50-55 \mathrm{ml})$ was added to the crude product and heated with stirring, so unreacted acid was removed. Heating was stopped and filter to give a product. The collected product was successively washed with distilled water $(100 \mathrm{ml})$ to remove residual boric acid and dried the product at room temperature to afford C 01 . The yield was $83-85 \%$, m.p. $164-166^{\circ} \mathrm{C}$ (lit), TLC (eluent:chloroform/ methanol. $90: 10 \mathrm{v} / \mathrm{v}$ ) Rf: 0.83, $1 \mathrm{H}$ NMR (400 MHz, DMSO) $\delta \mathrm{H}:$ 7.69-7.09
$(10 \mathrm{H}, \mathrm{ArH}), 6.82(2 \mathrm{H}, \mathrm{NH} 2), 4.92(1 \mathrm{H}, \mathrm{CH}), \mathrm{MS}(\mathrm{EI}, 70 \mathrm{eV}) \mathrm{m} / \mathrm{z}: 167,183$, $212(\mathrm{M}+1), 213(\mathrm{M}+2), 253,254,423,424$.

\section{2-(Phenylamino)benzamide (C 02): Purple color}

$\mathrm{N}$-Phenyl anthranilic acid (12.73 g, $0.06 \mathrm{~mol}$ ), urea (19.09 g), and boric acid $(5.09 \mathrm{~g})$ were mixed and triturated the mixture for 2-5 min. Then, the triturated mixture was directly heated without the solvent at the $160-180^{\circ} \mathrm{C}$ for $19-20$ mins. During the course of reaction, the reaction mixture was completely melted and then reappeared as product. Heating was removed and product was allowed to cool to room temperature. The aqueous ammonia solution (50-55 ml) was added to the crude product and heated with stirring, so unreacted acid was removed. Heating was stopped and filter to give a product. The collected product was successively washed with distilled water $(100 \mathrm{ml})$ to remove residual boric acid and dried the product at room temperature to give $\mathrm{C} 02$. The yield was $69-71 \%$, m.p. $165-169^{\circ} \mathrm{C}$ (lit), TLC (eluent: n-hexane/ethyl acetate. 70:30 v/v) $\mathrm{R}_{\mathrm{f}}: 0.82$, MS (EI, $70 \mathrm{eV}$ ) m/z: 170, 196, 197, $213(\mathrm{M}+1), 214(\mathrm{M}+2), 239,240,266,280$.

\section{2-Phenylacetamide (C 03): Fluffy white}

Phenylacetic acid ( $8.10 \mathrm{~g}, 0.06 \mathrm{~mol})$, urea (12.15 g), and boric acid $(3.24 \mathrm{~g})$ were mixed and triturated the mixture for $2-5 \mathrm{~min}$. Then, the triturated mixture was directly heated without the solvent at the $160-180^{\circ} \mathrm{C}$ for $29-30$ mins. During the course of reaction, the reaction mixture was completely melted and then reappeared as product. Heating was removed and product was allowed to cool to room temperature. The aqueous ammonia solution (50-55 ml) was added to the crude product and heated with stirring, so unreacted acid was removed. Heating was stopped and filter to give a product. The collected product was successively washed with distilled water $(100 \mathrm{ml})$ to remove residual boric acid and dried the product at room temperature to afford C 03 . The yield was $87-89 \%$, m.p. $155-160^{\circ} \mathrm{C}$ (lit), TLC (eluent: n-hexane/ethyl acetate. 70:30 v/v) $\mathrm{R}_{\mathrm{f}} 0.86,{ }^{1} \mathrm{H}$ NMR (400 MHz, DMSO) $\delta_{\mathrm{H}}: 7.67-6.68(5 \mathrm{H}, \mathrm{ArH}), 6.42\left(2 \mathrm{H}, \mathrm{NH}_{2}\right), 5.48(2 \mathrm{H}$, $\mathrm{CH}_{2}$ ), MS (EI, $\left.70 \mathrm{eV}\right) \mathrm{m} / \mathrm{z}:$ 91, $136(\mathrm{M}+1), 137(\mathrm{M}+2), 177,178,271,272$.

\section{4-Hydroxybenzamide (C 04): Pale yellow}

p-hydroxybenzoic acid (8.22 g, $0.06 \mathrm{~mol}$ ), urea (12.33 g), and boric acid (3.28 g) were mixed and triturated the mixture for 2-5 min. Then, the triturated mixture was directly heated without the solvent at the $160-180^{\circ} \mathrm{C}$ for $20-22$ mins. During the course of reaction, the reaction mixture was completely melted and then reappeared as product. Heating was removed and product was allowed to cool to room temperature. The aqueous ammonia solution $(50-55 \mathrm{ml})$ was added to the crude product and heated with stirring, so unreacted acid was removed. Heating was stopped and filter to give a product. The collected product was successively washed with distilled water $(100 \mathrm{ml})$ to remove residual boric acid and dried the product at room temperature to afford C 04 . The yield was $74-76 \%$, m.p. $120-124^{\circ} \mathrm{C}$ (lit), TLC (eluent:n-hexane/ethyl acetate. 70:30 v/v) $\mathrm{R}_{\mathrm{f}}: 0.88,{ }^{1} \mathrm{H}$ NMR (400 MHz, DMSO) $\delta_{\mathrm{H}}: 7.49-7.28\left(2 \mathrm{H}, \mathrm{NH}_{2}\right), 7.27-7.19$ (4H, ArH), 6.91 (1H, OH), MS (EI, 70 eV) m/z: 120, 137 (M), 138 (M+1), 161, 179, 234.

\section{4-Nitrobenzamide (C 05): Off white}

p-nitro benzoic acid (9.96 g, $0.06 \mathrm{~mol})$, urea (14.94 g), and boric acid ( $3.98 \mathrm{~g})$ were mixed and triturated the mixture for 2-5 min. Then, the triturated mixture was directly heated without the solvent at the $160-180^{\circ} \mathrm{C}$ for $14-15$ mins. During the course of reaction, the reaction mixture was completely melted and then reappeared as product. Heating was removed and product was allowed to cool to room 
temperature. The aqueous ammonia solution (50-55 ml) was added to the crude product and heated with stirring, so unreacted acid was removed. Heating was stopped and filter to give a product. The collected product was successively washed with distilled water $(100 \mathrm{ml})$ to remove residual boric acid and dried the product at room temperature to afford C 05 . The yield was $78-80 \%$, m.p. $180-183^{\circ} \mathrm{C}$ (lit), TLC (eluent: n-hexane/ethyl acetate. 70:30 v/v) R: 0.91, MS (EI, $70 \mathrm{eV}$ ) m/z: 98, 114, 124, $166(M), 167(M+1), 208$.

\section{RESULTS AND DISCUSSION}

Our study is focused on the formation of an amide from the carboxylic acid and urea, catalyzed by boric acid [17]. It consists of two simple steps, (1) mixing and trituration of acid, urea, and boric acid (2) direct heating (without the solvent) of the triturated mixture to gives a product/amide.

This reaction can be carried out directly in the beaker on the hot plate. The first and foremost important step in this technique is the mixing and trituration of the reactants. Mixing and trituration cause the melting point depression of the reaction components. Hence, they can be easily melted at the reaction temperature and formed the product/ amide within 10-30 min. The product or amide not formed or formed in a minor amount when the reaction mixture not got melted at the reaction temperature.

During the course of reaction, pyrolysis of urea liberates the ammonia. Hence, urea is act as a suitable source for in situ generation of ammonia. Moreover, the carboxylic acid reacts with the boric acid to forms a mixed anhydride (actual acylating agent) [18].

Now, ammonia and mixed anhydride reacted together to forms the desired amides and regenerates the catalytically active boric acid. The possible mechanism of the reaction has shown in Fig. 1.

The mixed anhydride is an activated form of the acid and it is the actual reacting species [19]. In contrast to conventional methods, the mixed anhydride is in situ formed and only catalytic amount is present at any time during the course of reaction. As the reaction temperature is $160-180^{\circ} \mathrm{C}$. Hence, the water liberated from the reaction getting continuously eliminated by evaporation. Hence, the reaction equilibrium got shifted in the direction of the product formation and the reaction rate noticeably increases.

We have synthesized the amides from the structurally diverse carboxylic acid. The method can tolerate a wide range of function groups $\left(-\mathrm{NO}_{2},-\right.$ $\mathrm{OH},-\mathrm{X},-\mathrm{OCH}_{3}$ ) under given reaction conditions.
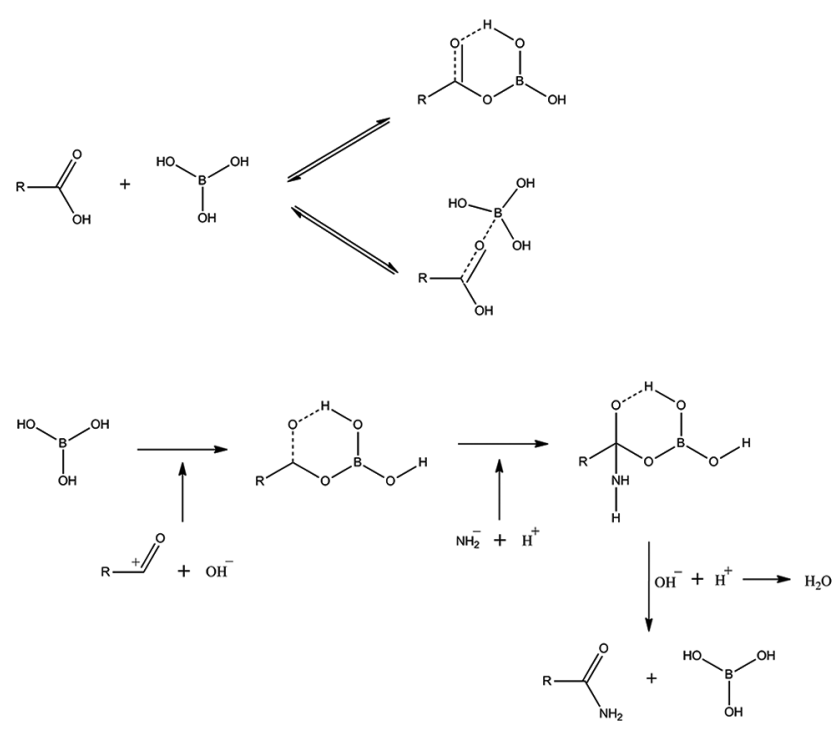

Fig. 1: Mechanism of the amide formation $[17,19]$
The presence of a hydroxyl group on the aromatic ring lowered the yield. Moreover, the presence of nitro group (electron-withdrawing groups) on the aromatic ring increases the rate of reaction and yields [7].

Our process has several advantages over the other processes are: It eliminates byproducts, minimizes impurity, and forms the products in good yield and purity [20].

The advantages are as follow:

- Greener method

- Simple procedure

- Short reaction time (6-16 h in other methods)

- Solvent-less/solid-state/dry media method.

The reported method can be applied to a wide range of acids. It can easily afford the amides in high purity. The main limitation of this method is that thermo-labile compounds get decomposed.

\section{CONCLUSION}

We have developed a Greener method for the synthesis of amide under solvent-free condition. In this method, amide has been formed directly from the acid and urea in the presence of boric acid as a catalyst.

The process is quick, convenient, and includes the green catalyst. We have synthesized the amides from various types of acids, like unsubstituted, substituted, monocyclic, and bicyclic acid. Hence, this method can be applied to various amidation reactions. The reaction is having a high rate of reaction or shorter reaction time. It is a simple and solvent-less method; hence, it follows the principles of green chemistry. However, there is a need to evaluate the applicability of this method to the aliphatic acids.

\section{ACKNOWLEDGMENTS}

The authors acknowledge the support provided by the Department of Pharmaceutical Chemistry, Shree Dhanvantary Pharmacy College, Kim(E), Dist.: Surat 394 110, Gujarat, India.

\section{AUTHORS' CONTRIBUTIONS}

Both the authors contributed equally.

\section{CONFLICTS OF INTEREST}

The authors declare no conflicts of interest.

\section{SOURCE OF FUNDING}

This paper was not supported by any grant or funding.

\section{SUPPLEMENTARY MATERIAL}

${ }^{1} \mathrm{H}$ NMR and mass spectra are available in the compressed file attach with the manuscript.

\section{REFERENCES}

1. Valeur E, Bradley M. Amide bond formation: Beyond the myth of coupling reagents. Chem Soc Rev 2009;38:606-31.

2. Machetti F, Bucelli I, Indiani G, Kappe CO, Guarna A. Parallel synthesis of an amide library based on the 6,8-dioxa-3-azabicyclo[3.2.1] octane scaffold by direct aminolysis of methyl esters. J Comb Chem 2007;9:454-61.

3. Pattabiraman VR, Bode JW. Rethinking amide bond synthesis. Nature 2011;480:471-9.

4. Xiao F, Liu Y, Tang C, Deng GJ. Peroxide-mediated transitionmetal-free direct amidation of alcohols with nitroarenes. Org Lett 2012;14:984-7.

5. Ghose AK, Viswanadhan VN, Wendoloski JJ. A knowledge-based approach in designing combinatorial or medicinal chemistry libraries for drug discovery. 1. A qualitative and quantitative characterization of known drug databases. J Comb Chem 1999;1:55-68.

6. Lanigan RM, Sheppard TD. Recent developments in amide synthesis: 
Direct amidation of carboxylic acids and transamidation reactions. Eur J Org Chem 2013;2013:7453-65.

7. Khalafi-Nezhad A, Mokhtari B, Soltani Rad MN. Direct preparation of primary amides from carboxylic acids and urea using imidazole under microwave irradiation. Tetrahedron Lett 2003;44:7325-8.

8. Leggio A, Belsito EL, De Luca G, Di Gioia ML, Leotta V, Romio E, et al. One-pot synthesis of amides from carboxylic acids activated using thionyl chloride. RSC Adv 2016;6:34468-75.

9. Swamy T, Raviteja P, Subba Reddy BV, Ravinder V. Efficient method for the synthesis of benzamides from benzoic acids and aryl isothiocyanates using $\mathrm{K}_{2} \mathrm{HPO}_{4}$. ChemistrySelect 2017;2:7612-4.

10. Crochet P, Cadierno V. Catalytic synthesis of amides via aldoximes rearrangement. Chem Commun 2015;51:7612-4.

11. Constable DJ, Dunn PJ, Hayler JD, Humphrey GR, Leazer JL Jr., Linderman RJ, et al. Key green chemistry research areas--a perspective from pharmaceutical manufacturers. Green Chem 2007;9:411-20.

12. Kidwai M. Dry media reactions. Pure Appl Chem 2001;73:147-51.

13. Ivanković A, Dronjić A, Bevanda AM, Talić S. Review of 12 principles of green chemistry in practice. Int J Sustain Green Energy 2017;6:39-48.
14. Marvaniya HM, Modi KN, Sen DJ. Greener reactions under solvent free conditions. Int J Drug Dev Res 2011;3:42-51.

15. Mylavarapu RK, Kondaiah GC, Kolla N, Veeramalla R, Koilkonda P, Bhattacharya A, et al. Boric acid catalyzed amidation in the synthesis of active pharmaceutical ingredients. Org Process Res Dev 2007;11:1065-8.

16. Kamali M, Shockravi A, Doost MS, Hooshmand SE. One-pot, solventfree synthesis via Biginelli reaction: Catalyst-free and new recyclable catalysts. Cogent Chem 2015;1:1081667.

17. Ge C, Li L, Zhang R, Wang R, Zhang X. Amidation of aromatic amine and benzoic acid under boric acid catalysis. Asian J Chem 2014;26:6805-7.

18. Tang T. Boric acid catalyzed amide formation from carboxylic acids and amines: N-benzyl-4-phenylbutyramide. Org Synth 2005;81:262-72.

19. Arce G, Carrau G, Bellomo A, Gonzalez D. Greener synthesis of an amide by direct reaction of an acid and amine under catalytic conditions. World J Chem Educ 2015;3:27-9

20. Jursic BS, Zdravkovski ZA. Simple preparation of amides from acids and amines by heating of their mixture. Synth Commun 1993;23:2761-70. 